Vol 2 No 1 (2018) Page $102-110$

JURNAL OBSESI : JURNAL PENDIDIKAN ANAK USIA DINI

Research \& Learning in Early Childhood Education https://obsesi.or.id/index.php/obsesi

\title{
Pengaruh Kirigami Terhadap Kemampuan Motorik Halus Anak di Taman Kanak-Kanak
}

\author{
Rakimahwati $^{1}$, Nora Agus Lestari ${ }^{2}$, Sri Hartati ${ }^{3}$ \\ PG-PAUD, Fakultas Ilmu Pendidikan, Universitas Negeri Padang
}

\begin{abstract}
ABSTRAK
Penelitian kuantitatif ini berbentuk Quasi-Eksperimen. Penelitian ini bertujuan untuk membuktikan adanya pengaruh kegiatan kirigami terhadap kemampuan motorik halus anak usia dini di Taman Kanak-Kanak Yayasan Amalan Parupuk Tabing Padang. Sampel penelitian ini berjumlah 24 anak kelompok B, terdiri dari kelas B1 (Kelas Eksperimen) dan kelas B2 (Kelas kontrol). Penelitian ini menggunakan teknik pengumpulan data berupa tes perbuatan guru, berupa pernyataan sebanyak 5 butir item pernyataan. Hasil penelitian menunjukkan bahwa anak kelas eksperimen menggunakan kirigami memiliki rata-rata lebih tinggi jika dibandingkan dengan kelas kontrol yang menggunakan origami alam semesta. Angka rata-rata kelas eksperimen yaitu 83,25 dan angka rata-rata kelas kontrol yaitu 76. Berdasarkan analisis data yang telah dilakukan bahwa $t_{\text {hitung }}>t_{\text {tabel, }}$ yaitu 2,161>2,07387. Dengan demikian dapat disimpulkan bahwa kirigami berpengaruh terhadap kemampuan motorik halus anak usia dini.
\end{abstract}

Kata Kunci: Kirigami; Kemampuan motorik halus anak.

\begin{abstract}
ABSTRACK
The method used of research Quasi Eksperimental design. The purpose of this study was to prove the influence of kirigami to the fine motor skills of Ability of early childhood at Taman Kanak-Kanak Yayasan Amalan Parupuk Tabing Padang. Use 12 childeren in class B1 as the experiment class and use the and use the 12 children in class of B2 as control class. Data collected by teacher-made tests, in form of statements as many 5 item. The results showed that the experimental class children using kirigami had a higher average when compared with the control class that used the origami alam semesta. The average number of experimental class is 83.25 and the control class average is 76. Based on data analysis that thitung $>t_{\text {tabel }} 2,161>2,07387$. And than using kirigami affect the fine motor skilss of 5-6 year age in Taman Kanak-Kanak Yayasan Amalan Parupuk Tabing Padang.
\end{abstract}

Keywords: Kirigami; fine motor skills child.

@ Jurnal Obsesi Prodi PG-PAUD FIP UPTT 2018

$\triangle$ Corresponding author : Rakimahwati

Address : PG-PAUD, FIP, UNP Padang

Email : rakimahwati10@yahoo.com

ISSN 2356-1327 (Media Cetak)

Phone : 081363411858 


\section{PENDAHULUAN}

Anak usia dini adalah anak yang masuk dalam rentang usia 0-6 tahun yang terbagi menjadi tiga kelompok bayi hingga umur 2 tahun, kelompok umur 3 tahun hingga kelompok umur 5 tahun, dan kelompok umur 6 tahun. Menurut Mutiah (2010:6) anak usia dini merupakan individu yang unik dan memiliki karakteristik tersendiri sesuai sesuai dengan tahapan usianya.

Anak adalah anak. Menurut Gita (2014:1) Melalui pemberian rangsangan pendidikan untuk membantu anak mengembangkan dan mennumbuhkan jasmani dan rohaninya. Pendidikan anak usia dini menitikberatkan pada peletakan dasar ke arah pertumbuhan dan perkembangan fisik (koordinasi motorik halus dan kasar), kecerdasan (daya pikir, daya cipta, kecerdasan emosi, kecerdasan spritual), sosio-emosional (sikap dan perilaku serta agama) bahasa dan komunikasi, sesuai dengan keunikan dan tahaptahap perkembangan yang dilalui anak.

Pendidikan anak usia dini merupakan pendidikan yang paling mendasar dan menempati kedudukan sebagai golden age, dan merupakan suatu upaya pembinaan yang ditujukan bagi anak sejak lahir sampai dengan anak usia enam tahun, yang dilakukan melalui pemberian rangsangan pendidikan untuk membantu pertumbuhan dan perkembangan jasmani dan rohani, agar anak memiliki kesiapan dalam memasuki pendidikan lebih lanjut. Peraturan Menteri Pendidikan dan Kebudayaan Republik Indonesia Nomor 137 Tahun 2014 Tentang Standar Nasional Pendidikan Anak Usia Dini Pasal 1 Dalam Peraturan Menteri ini yang dimaksud dengan Standar Nasiona Pendidikan Anak Usia Dini selanjutnya disebut Standar PAUD adalah kriteria tentang pengelolaan dan penyelenggaraan PAUD diseluruh wilayah hukum Negara Kesatuan Republik Indonesia. Pendidikan Anak Usia Dini adalah upaya pembinaan yang ditujukan kepada anak sejak lahir sampai usia 6 (enam) tahun yang dilakukan melalui pemberian rancangan pendidikan untuk membantu pertumbuhan dan perkembangan jasmani dan rohani agar anak memiliki kesiapan dalam memasuki pendidikan lebih lanjut.

Pendidikan anak usia dini khususnya di Taman Kanak-Kanak perlu mengembangkan motorik anak dengan berbagai macam keterampilan, karena anak yang memiliki unsur-unsur motorik akan merasa senang apabila dapat menyelesaikan tugas keterampilan motorik dan merasa puas apabila dapat melihat hasilnya dengan baik. Menurut Santrock (2007: 216) "keterampilan motorik halus merupakan keterampilan motorik yang melibatkan gerakan yang diatur secara halus". Menurut Beaty (2014:236) "perkembangan motorik meliputi motorik kasar dan motorik halus". Artinya motorik kasar merupakan perkembangan otot-otot kasar anak yang terkoordinasi seperti berjalan, berlari, melompat dan melempar. Sedangkan motorik halus adalah gerakan yang menggunakan otototot halus atau sebagian anggota tubuh tertentu, yang dipengaruhi oleh kesempatan untuk belajar dan berlatih. Misalnya, kemampuan memindahkan benda dari tangan, mencoretcoret, menyusun balok, menggunting, menulis dan sebagainya. Kedua kemampuan tesebut sangat penting agar anak bisa berkembang dengan optimal (Novitawati, 2014)

Senada dengan pernyataa diatas fauziddin menyatakan bahwa Pendidikan anak usia dini merupakan salah satu bentuk penyelenggaraan pendidikan yang menitik beratkan pada peletakan dasar kearah pertumbuhan dan perkemba- ngan fisik (koordinasi motorik halus dan kasar), kecerdasan, daya cipta, kecerdasan emosi, kecerdasan jamak dan kecerdasan spiritual.(Fauziddin, 2016)

Berdasarkan penejelasan di atas mengungkapkan bahwa perlu adanya suatu kegiatan untuk mengasah dan mengembangkan kemampuan motorik halus anak. Selain itu, perlu adanya suatu kegiatan yang membantu agar otot halus pada tangan dapat bergerak, khusunya pada jari-jemari tangan anak.

Saat memilih kegiatan dalam proses pembelajaran untuk anak, ada beberapa hal yang perlu diperhatikan. Salah satunya adalah menyesuaikan dengan tingkat pencapaian perkembangan motorik halus anak. Menurut Kurikulum 2013 anak usia dini, bahwa tingkat pencapaian perkembangan kemampuan motorik halus anak anak kelompok usia $5 \leq 6$ tahun adalah: Dengan indikator motorik halus anak dapat membuat garis vertikal/horizontal, lengkung kiri/kanan, miring kiri/kanan, dan lingkaran, dapat menggambar sesuai dengan gagasannya, dapat menggunakan alat tulis dengan benar, dapat menggunting sesuai dengan pola, serta melipat bentuk.(Indonesia, 2003) 
Motorik halus dan motorik kasar dapat dikembangkan dengan permainan. Penelitian sebelumnya yang dilakukan oleh Hidayatu Munawaroh dengan menggunakan permainan engklek ditemukan data bahwa Permainan ini dapat dimanfaatkan untuk mengembangkan potensi diri anak meliputi aspek nilai moral agama, aspek kognitif, aspek bahasa, aspek fisik motorik, dan aspek seni, serta pengenalan budaya.(Munawaroh, 2017)

Sedangkan pada pe

Terkait dari hasil pengamatan dan observasi awal yang dilakukan oleh peneliti di Taman Kanak-kanak Yayasan Amalan Parupuk Tabing Padang menunjukkan bahwa anak-anak pada umumnya memiliki kemampuan motorik halus yang belum optimal. Hal ini terlihat dari jumlah 12 anak diketahui bahwa kemampuan motorik halus dalam hal menggunting sesuai pola yang dimiliki anak di Kelompok B1 terdapat permasalahan. Terdapat $48 \%$ anak ketika melaksanakan kegiatan melipat dan menggunting hasilnya tidak sesuai dengan pola, tidak rapi, dan sebagiannya robek. Ketika kegiatan menempel gambar anak melakukannya masih berantakan. Faktor-faktor penyebab dari permasalahan aspek perkembangan motorik halus yang ada di Taman Kanak-kanak Yayasan Amalan Parupuk Tabing Padang yaitu, sesuai kenyataan dilapangan guru menerapkan pembelajaran untuk perkembangan kemampuan motorik halus masih dengan kegiatan mewarnai gambar dengan krayon, melakukan kolase dengan potongan-potongan kertas, meronce dengan benang dan sedotan serta kegiatan finger painting sehingga kegiatan membuat anak bosan.

Pemberian stimulasi yang tepat bagi anak sangat penting bagi membantu perkembangan anak. Tumbuh kembang anak dapat distimulasi dengan berbagai kegiatan yang menarik minat anak. Salah satu kegiatan yang menarik minat anak adalah kirigami.

Kirigami adalah seni melipat. memotong atau menggunting kertas menjadi sebuah bentuk yang kreatif, bahan yang dibutuhkan juga mudah untuk ditemui seperti kertas, gunting dan lem. Kirigami dapat mengembangkan pembelajaran dibidang seni, matematika, desain grafis, dan koordinasi matatangan. Hal ini sesuai dengan pernyataan yang dikemukakan oleh Temko (2014:4) sebagai berikut.
Kirigami, the creative art of papercutting, is a surprisingly easy craft that requires only paper, a pair of scissors, and sometimes glue. Cutting paper seems to be an instinctive pleasure. At an early age many children like to snip paper into small pieces. Before long they design pictures by pasting to shapes on a background. Papercutting is well recognized to provide educational benefits in the areas of art, math, grapich design, and hand-eye coordination.

"Kirigami sendiri merupakan seni memotong kertas yang bisa dipelajari dengan mudah hanyadengan berbekal gunting atau cutter pada kertas" menurut Mitarwan (2011:6). Dalam perkembangannya kirigami dimulai pada tataran yang cukup kompleks dari membuat bentuk dua dimensi maupun tiga dimensi.

Terkait dengan berbagai permasalahan di atas maka dilakukan kegiatan kirigami dalam kegiatan pembelajaran anak bertujuan agar kemampuan motorik halus masing-masing anak berkembang dan terlatih. Oleh karena itu, peneliti tertarik untuk melakukan penelitian "Pengaruh Kirigami terhadap kemampuan motorik halus anak usia dini di Taman Kanakkanak Yayasan Amalan Parupuk Tabing Padang”.

Berdasarkan latar belakang permasalah di atas, maka peneliti merumuskan masalah yakni, "seberapa besar pengaruh kirigami terhadap kemampuan motorik halus anak di Taman Kanak-kanak Yayasan Amalan Parupuk Tabing Padang”. Tujuan untuk mengetahui pengaruh kirigami terhadap kemampuan motorik halus anak di Taman Kanak-kanak Yayasan Amalan Parupuk Tabing Padang”.

\section{METODE}

Berdasarkan permasalahan yang diteliti yaitu Pengaruh Kirigami Terhadap Kemampuan Motorik Halus Anak Usia Dini di Taman Kanak-kanak Yayasan Amalan Parupuk Tabing Padang", maka bentuk penelitian ini adalah kuantitatif, dengan jenis penelitian Quasi Eksperiment (eksperimen semu). Sugiyono (2015:7) penelitian eksperimen merupakan suatu penelitian yang berusaha mencari pengaruh variabel tertentu terhadap variabel yang lain dalam kondisi yang terkontrol. Selanjutnya quasi eksperimental mempuanyai kelompok kontrol, tetapi tidak 
dapat berfungsi sepenuhnya untuk mengontrol variabel-variabel luar yang mempengaruhi pelaksanaan eksperimen.

Populasi dalam penelitian ini adalah seluruh kelompok B TK Yayasan Amalan Parupuk Tabing Padang yang terdaftar pada semester II Tahun Ajaran 2017/2018. Tk Yayasan Amalan Parupuk Tabing Padang memiliki jumlah siswa sebanyak 24 orang. Adapun teknik pengambilan sampel dalam penelitian adalah teknik purposive sampling. Sampel dalam penelitian ini adalah kelompok B1 dan B2. Kelompok B1 dijadikan eksperimen dan kelompok B2 dijadikan kelompok kontrol. Adapun jumlah sampel untuk setiap anak adalah kelompok B1 sebanyak 12 anak sebagai kelompok eksperimen dan kelompok B2 sebanyak 12 anak sebagai kelompok kontrol.

Teknik pengumpulan data yang digunakan dalam penelitian ini adalah tes buatan guru. Tes dikatakan valid apabila tes itu dapat mengukur apa yang hendak diukur. Instrumen ini menggunakan format checklist untuk penilaiannya. Dengan kriteria penilaian yaitu Berkembang Sangat Baik diberi skor 4, Berkembang Sesuai Harapan diberi skor 3, Mulai Berkembang 2, Belum berkembang 1.

Adapaun teknik analisis data yang digunakan penelitian ini adalah membandingkan perbedaan dari dua rata-rata nilai, sehingga dilakukan dengan uji t (t-test). Namun sebelum itu terlebih dahulu melakukan uji normalitas dan uji homogenitas. Sebelum melakukan analisis perbedaan tersebut, perlu dilakukan uji normalitas dengan uji liliefors, dan uji homogenitas dengan uji barlett. Jika sudah diketahui sebuah data berdistribusi normal dan bersifar homogen baru dilakukan analisis data sesuai dengan teknik analisis yang telah dilakukan yaitu dengan mencari perbandingan dengan menggunakan t-test.

\section{HASIL PENELITIAN}

Data yang dideskripsikan dalam penelitian ini terdiri dari dari dua kelompok yaitu data tentang hasil pre-test di kelas eksperimen (B1) dan di kelas kontrol (B2) terhadap kemampuan motorik halus anak sebelum diberikan treatment.
Tabel 1.Rekapitulasi Hasil Pre-test Kemampuan Motorik Halus Anak di Kelas Eksperimen dan Kelas Kontrol

\begin{tabular}{|l|c|c|}
\hline \multirow{2}{*}{ Variabel } & \multicolumn{2}{|l|}{ Pembelajaran } \\
\cline { 2 - 3 } & $\begin{array}{l}\text { Eksperimen } \\
\text { B1 }\end{array}$ & $\begin{array}{l}\text { Kontrol } \\
\text { B2 }\end{array}$ \\
\hline $\mathrm{N}$ & 12 & 12 \\
\hline $\begin{array}{l}\text { Nilai } \\
\text { tertinggi }\end{array}$ & 75 & 75 \\
\hline $\begin{array}{l}\text { Nilai } \\
\text { terendah }\end{array}$ & 55 & 50 \\
\hline Jumlah nilai & 790 & 735 \\
\hline Median & 67,5 & 64,5 \\
\hline Rata-rata & 65,8 & 61,2 \\
\hline SD & 6,06 & 8,1 \\
\hline SD & 36,72 & 65,61 \\
\hline
\end{tabular}

Berdasarkan tabel 2 di atas, kelas ekperimen dengan jumlah 12 orang anak memperoleh nilai tertinggi 75 dan nilai terendah 50. Dari nilai anak kelas eksperimen ini diperoleh jumlah nilai secara keseluruhan 790 median 69,5 dengan rata-rata nilai sebesar 65,8 standar deviasinya 6,06 dan nilai variansnya sebanyak 36,72 .

Sedangkan kelas kontrol dengan jumlah anak 12 orang memperoleh nilai tertinggi 75 dan nilai terendah 50. Dari nilai anak kelas kontrol ini diperoleh jumlah nilai secara keseluruhan 735 , median 64,5 dengan rata-rata nilai sebesar 61,2 standar deviasinya 8,1 dan nilai variansnya adalah 36,72 .

Tabel 3.Rekapitulasi Hasil Post-test Kemampuan Motorik Eksperimen melalui kirigami dan Kelas Kontrol melalui Origami Alam Semesta

\begin{tabular}{|l|l|l|}
\hline \multirow{2}{*}{ Variabel } & \multicolumn{2}{|l|}{ Pembelajaran } \\
\cline { 2 - 3 } & $\begin{array}{l}\text { Eksperimen } \\
\text { B1 }\end{array}$ & $\begin{array}{l}\text { Kontrol } \\
\text { B2 }\end{array}$ \\
\hline $\mathrm{N}$ & 12 & 12 \\
\hline $\begin{array}{l}\text { Nilai } \\
\text { tertinggi }\end{array}$ & 95 & 85 \\
\hline $\begin{array}{l}\text { Nilai } \\
\text { terendah }\end{array}$ & 70 & 65 \\
\hline Jumlah nilai & 975 & 895 \\
\hline Median & 83,25 & 76 \\
\hline Rata-rata & 81,2 & 74,5 \\
\hline SD & 8,1 & 6,60 \\
\hline SD & 65,61 & 43,56 \\
\hline
\end{tabular}

Berdasarkan tabel 3 di atas, kelas ekperimen dengan jumlah 12 orang anak memperoleh nilai tertinggi 95 dan nilai terendah 65. Dari nilai anak kelas eksperimen ini 
diperoleh jumlah nilai secara keseluruhan 975 , median 83,25 dengan rata-rata nilai sebesar 81,2 standar deviasinya 8,1 dan nilai variansnya sebanyak 65,61 .

Sedangkan kelas kontrol dengan jumlah anak 12 orang memperoleh nilai tertinggi 85 dan nilai terendah 65. Dari nilai anak kelas kontrol ini diperoleh jumlah nilai secara keseluruhan 895 , median 76 dengan ratarata nilai sebesar 74,5 standar deviasinya 76 dan nilai variansnya adalah 43,56.

Adapun hasil penelitian anak yaitu kemampuan motorik halus anak pada kelas ekspeimen dan kelas kontrol, diperoleh hasil bahwa kemampuan motorik halus anak di kelas eksperimen (kelompok B1) lebih tinggi dibandingkan pada kelas kontrol (kelompok B2).

Uji normalitas kelas eksperimen dan kelas kontrol diperoleh harga $\mathrm{L}_{0}$ dan $\mathrm{L}_{\mathrm{t}}$ pada taraf nyata 0,05 untuk $\mathrm{N}=12$ seperti pada tabel berikut:

Tabel 4 .Hasil Perhitungan Uji Liliefors Kelas Eksperimen dan Kelas Kontrol (Pre-test)

\begin{tabular}{|l|l|l|l|l|l|l|}
\hline No & Kelas & $\mathbf{N}$ & $\mathrm{A}$ & $\mathbf{L}_{\mathbf{0}}$ & $\mathbf{L}_{\mathbf{t}}$ & $\begin{array}{l}\text { Kete- } \\
\text { rangan }\end{array}$ \\
\hline 1 & $\begin{array}{l}\text { Ekpe- } \\
\text { rimen }\end{array}$ & 12 & 0,05 & 0,162 & 0,242 & Normal \\
\hline 2 & $\begin{array}{l}\text { Kontro } \\
1\end{array}$ & 12 & 0,05 & $\begin{array}{l}0,166 \\
2\end{array}$ & 0,242 & Normal \\
\hline
\end{tabular}

Berdasarkan tabel 4 terlihat bahwa kelompok eksperimen nilai $\mathrm{L}_{\text {hitung }} 0,162$ lebih kecil dari $\mathrm{L}_{\text {tabel }} 0,242$ untuk $\alpha=0,05$. Dengan demikian nilai kelompok eksperimen berasal dari data yang berdistribusi normal. Untuk kelas kontrol, diperoleh $\mathrm{L}_{\text {hitung }} 0,1662$ lebih kecil dari $\mathrm{L}_{\text {tabel }} 0,242$ untuk $\alpha=0,05$. Ini berarti bahwa nilai kelompok kontrol berasal dari data yang berdistribusi normal.

Pengujian persyaratan yang kedua adalah pengujian Homogenitas dengan menggunakan uji Bartlett. Pengujian ini bertujuan untuk mengetahui apakah data berasal dari kelompok yang homogen, antara kelas eksperimen dan kelas kontrol. Jika chi kuadrat hitung < chi kuadrat tabel, berarti data berasal dari kelompok yang homogen. Jika hasil perhitungan dari $X^{2}{ }_{\text {hitunglebihkecildari } X^{2} \text { tabel }}$ berarti bahwa data berasal dari kelompok yang homogen, sebaliknya jika

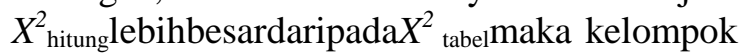
tersebut tidak homogen".
Tabel 5. Hasil Perhitungan Uji Homogenitas Kelas Eksperimen dan Kelas Kontrol

\begin{tabular}{|l|l|l|l|l|}
\hline Kelas & $\boldsymbol{\alpha}$ & $X^{2}{ }_{\text {hitung }}$ & $X_{\text {tabel }}^{2}$ & Kesimpulan \\
\cline { 1 - 2 } $\begin{array}{l}\text { Eksperi- } \\
\text { men }\end{array}$ & \multirow{2}{*}{0,05} & 0,124 & 3,841 & Homogen \\
\cline { 1 - 2 } Kontrol & & & & \\
\hline
\end{tabular}

Berdasarkan tabel dapat dilihat bahwa

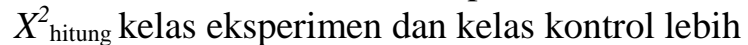
kecil dari $X^{2}$ tabel $\left(X^{2}{ }_{\text {hitung }}<X_{\text {tabel }}^{2}\right)$, berarti kelas eksperimen dan kelas kontrol memiliki varians yang homogen.

Setelah dilakukan uji normalitas dan uji homogenitas, diketahui bahwa kedua kelas sampel berdistribusi normal dan mempunyai varians homogen. Selanjutnya dilakukan pengujian hipotesis dengan menggunakan teknik t-tes.

Jika $\mathbf{t}_{\text {hitung }}>\mathbf{t}_{\text {tabel }}$ maka $\mathrm{H}_{0}$ ditolak dan $\mathrm{H}_{\mathrm{a}}$ diterima

Jika $\mathbf{t}_{\text {hitung }}<\mathbf{t}_{\text {tabel }}$ maka $\mathrm{H}_{0}$ diterima dan $\mathrm{H}_{\mathrm{a}}$ ditolak

Berikut ini akan digambarkan pengolahan data dengan t-test:

Tabel 6. Hasil Perhitungan Nilai Kelas Ekperimen dan Kontrol (pre-test)

\begin{tabular}{|l|l|l|}
\hline Aspek & $\begin{array}{l}\text { Kelas } \\
\text { Eksperimen }\end{array}$ & $\begin{array}{l}\text { Kelas } \\
\text { Kontrol }\end{array}$ \\
\hline $\mathrm{N}$ & 12 & 12 \\
\hline $\bar{X}$ & 65,8 & 61,2 \\
\hline $\mathrm{SD}^{2}$ & 36,72 & 65,61 \\
\hline
\end{tabular}

Untuk menguji hipotesis digunakan ttest. Dari hasil uji hipotesis dengan menggunakan t-test diperoleh hasil sebagai berikut:

Tabel 7. Hasil Perhitungan Pre-test Pengujian dengan $t$-test

\begin{tabular}{|l|l|l|l|l|l|l|}
\hline $\mathbf{N}$ & Kelas & $\mathbf{N}$ & $\begin{array}{l}\text { Hasil } \\
\text { Rata-rata }\end{array}$ & thitung & $\begin{array}{l}\text { tabel } \\
\mathbf{a 0 , 0 5}\end{array}$ & Keputusan \\
\hline $\mathbf{y}$ & $\begin{array}{l}\text { Eksperi } \\
\text { men }\end{array}$ & 12 & 65,8 & \multirow{2}{*}{1,513} & 2,07387 & Terima H0 \\
\cline { 1 - 3 } $\mathbf{2}$ & Kontrol & 12 & 61,2 & & & \\
\hline
\end{tabular}

Dilihat dari tabel di atas untuk taraf nyata $\alpha=0,05(5 \%)$ dengan df sebesar 22 adalah $=$ 2,07387. Dengan demikian, dapat diketahui bahwa pada taraf nyata $\alpha=0,05(5 \%)$, $\mathbf{t}_{\text {hitung lebih kecil dari pada } \mathbf{t}_{\text {tabel }}}$ $(\mathbf{0}, \mathbf{6 2 1 5}<\mathbf{2 , 0 7 3 8 7})$. Jadi, dapat disimpulkan 
bahwa tidak terdapat perbedaan yang signifikan antara kemampuan motorik halus anak di kelas eksperimen dan kontrol dalam nilai pre-test.

Data post-test penelitian kelas eksperimen dan kelas kontrol diolah untuk menentukan uji normalitas. Pada uji normalitas ini digunakan uji Liliefors seperti yang dikemukakan pada teknik analisis data. Analisis normalitas pada kelompok eksperimen dan kelompok kontrol.

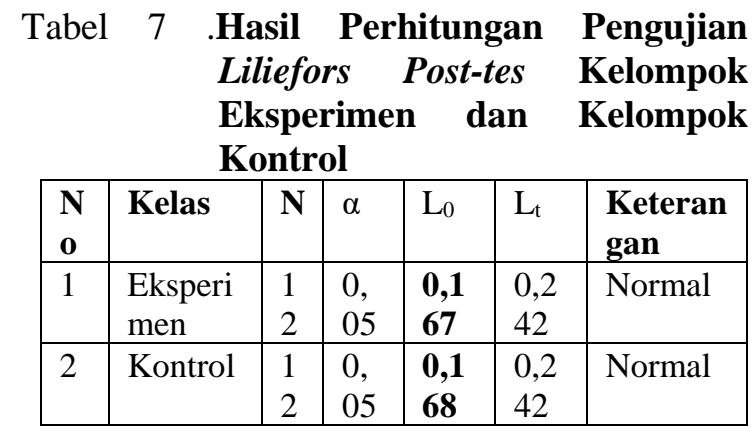

Berdasarkan tabel di atas terlihat bahwa kelompok eksperimen nilai $\mathrm{L}_{\text {hitung }} \mathbf{0 , 1 6 7}$ lebih kecil dari $\mathrm{L}_{\text {tabel }} 0,242$ untuk $\alpha 0,05$. Dengan demikian nilai kelas eksperimen berasal dari data yang berdistribusi normal. Untuk kelas kontrol diperoleh $\mathrm{L}_{\text {hitung }} \mathbf{0 , 1 6 8}$ lebih kecil dari $\mathrm{L}_{\text {tabel }} 0,242$ untuk $\alpha 0,05$. Ini berarti bahwa data kelas kontrol berasal dari data yang berdistribusi normal.

Pengujian persyaratan yang kedua adalah pengujian Homogenitas dengan menggunakan uji Bartlett. Pengujian ini bertujuan untuk mengetahui apakah data berasal dari kelompok yang homogen, antara kelas eksperimen dan kelas kontrol. Jika chi kuadrat hitung < chi kuadrat tabel, berarti data berasal dari kelompok yang homogen.

Hal ini sesuai dengan apa yang dikemukakan oleh Syafril (2010) bahwa "jika hasil perhitungan dari $X^{2}$ hitunglebihkecildari $X^{2}$ tabel berarti bahwa data berasal dari kelompok yang homogen, sebaliknya jika $X_{\text {hitung }}^{2}$ lebihbesardaripada $X^{2}$ tabel maka kelompok tersebut tidak homogen".

Hasil perhitungan diperoleh $X_{\text {hitung }}^{2}$ sebesar 1,4386 dapat dilihat pada tabel berikut:
Tabel 7. Hasil Perhitungan Uji Homogenitas Kelas Eksperimen dan Kelas Kontrol (posttest)

\begin{tabular}{|l|l|l|l|l|}
\hline Kelas & $\boldsymbol{\alpha}$ & $X^{2}{ }_{\text {hitung }}$ & $X_{\text {tabel }}^{2}$ & Kesimpulan \\
\hline $\begin{array}{l}\text { Ekspe- } \\
\text { rimen }\end{array}$ & \multirow{2}{*}{0,05} & 0,5456 & 3,841 & Homogen \\
\cline { 1 - 2 } Kontrol & & & & \\
\hline
\end{tabular}

Dari tabel dapat dilihat bahwa $X^{2}$ hitung kelas eksperimen dan kelas kontrol lebih kecil dari $X_{\text {tabel }}^{2}\left(X_{\text {hitung }}^{2}<X_{\text {tabel }}^{2}\right)$, berarti kelas eksperimen dan kelas kontrol memiliki varians yang homogen.

Tabel 8. Hasil Perhitungan Nilai Kelas Eksperimen dan Kelas Kontrol

\begin{tabular}{|l|l|l|}
\hline Aspek & Kelas Eksperimen & Kelas Kontrol \\
\hline $\mathrm{N}$ & 12 & 12 \\
\hline $\bar{X}$ & 81,2 & 74,5 \\
\hline $\mathrm{SD}^{2}$ & 65,61 & 43,56 \\
\hline
\end{tabular}

Untuk menguji hipotesis digunakan ttest. Dari hasil uji hipotesis dengan menggunakan t-test diperoleh hasil sebagai berikut:

Tabel 9. Hasil Perhitungan Post- test Pengujian dengan $t$ - test

\begin{tabular}{|l|l|l|l|l|l|l|}
\hline No & Kelas & $\mathbf{N}$ & $\begin{array}{l}\text { Hasil } \\
\text { Rata- } \\
\text { rata }\end{array}$ & $t_{\text {hitung }}$ & $\begin{array}{l}\mathrm{t}_{\text {tabel }} \\
\mathbf{a ~ 0 , 0 5}\end{array}$ & $\begin{array}{l}\text { Kepu- } \\
\text { tusan }\end{array}$ \\
\hline $\mathbf{1}$ & $\begin{array}{l}\text { Ekspe- } \\
\text { rimen }\end{array}$ & 12 & 81,2 & $\mathbf{2 . 1 6 1}$ & 2,07387 & $\begin{array}{l}\text { Tolak } \\
\mathrm{H}_{0}\end{array}$ \\
\hline $\mathbf{2}$ & Kontrol & 12 & 74,5 & & \\
\hline
\end{tabular}

Berdasarkan tabel di atas dapat disimpulkan bahwa $\mathrm{H}_{\mathrm{a}}$ diterima yaitu : terdapat pengaruh yang signifikan antara hasil post-test di kelas eksperimen dan kelas kontrol dalam kegiatan kirigami terhadap kemampuan motorik halus anak di Taman Kanak-kanak Yayasan Amalan Parupuk Tabing Padang.

Dengan demikian dapat disimpulkan bahwa kemampuan motorik halus anak lebih berpengaruh dengan kirigami dibandingkan dengan origami alam semesta, terlihat dari nilai rata-rata yang berhasil dicapai anak yaitu kelompok eksperimen 81,2 sedangkan kelompok kontrol 74,5. 
Setelah dilakukan perhitungan nilai pre-test dan post-test kelompok eksperimen dan kontrol selanjutnya dilakukan perbandingan antara nilai pre-test dan nilai post-test, yang tujuannya melihat apakah ada ada perbedaan nilai post-test dengan nilai pre-test.

Nilai yang di dapat anak pada pre-test kelas eksperimen (B1), nilai tertinggi yang diperoleh oleh anak adalah 75 dan nilai terendah adalah 55 dengan median 67,5. Sedangkan kelas kontrol (B2) nilai tertinggi yang diperoleh anak yaitu 75 dan nilai terendah 50 dengan median 64,5.

Pada post-test nilai tertinggi di peroleh anak kelas eksperimen (B1) adalah 95 dan nilai terendah 70 dengan median 83,25. Sedangkan pada kelas kontrol (B2) post test nilai tertinggi yang diperoleh anak adalah 85 dan nilai terendah adalah 65 dengan median 76.

Perbandingan hasil perhitungan nilai pre-test dan post-test terlihat pada nilai tertinggi dan nilai terendah yang diperoleh anak dan terlihat pada rata-rata kelas eksprimen dan kelas kontrol dimana pada post-test rata-rata menjadi lebih meningkat dari rata-rata nilai pre-test setelah dilakukan treat-ment.

Untuk lebih jelasnya dapat dilihat

Grafik 1.

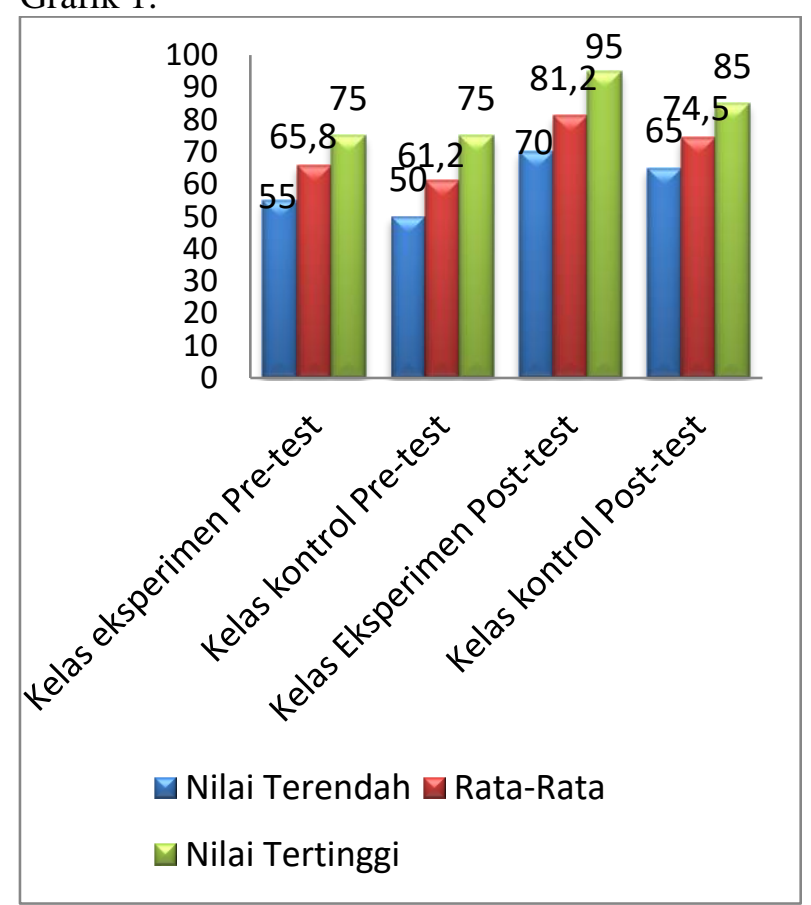

Grafik 1. Data perbandingan Hasil Pretest dan Post-test Kemampuan Motorik Halus Anak Kelas Eksperimen dan Kelas Kontrol

Pada pembelajaran dengan menggunakan kirigami, peneliti berfungsi sebagai fasilitator, yang bertugas memberikan pengarahan dan memberi contoh kepada anak. Dari uraian di atas, sangat jelas bahwa kirigami berpengaruh dalam mengembangkan kemampuan motorik halus anak.

\section{PEMBAHASAN}

Penelitian yang telah dilakukan dengan mengambil sampel 12 anak dengan rentang usia 5-6 tahun dan dilakukan sebanyak lima kali pertemuan terdiri dari satu kali pre-test, tiga kali treat-ment, satu kali post-test. Pada kelas eksperimen dilakukan peneliti dan pada kelas kontrol dilakukan oleh guru kelas yang diamati oleh peneliti pada pre-test dan post-test.

Berdasarkan hasil pre-test kemampuan motorik halus anak pada kelompok eksperimen dan kelompok kontrol pada pre-test diperoleh nilai rata-rata kelompok eksperimen yaitu 65,8. Angka rata-kelompok kontrol yaitu 61,2. Berdasarkan hasil analisis data yang telah dilakuakan bahwa thitung sebesar 1,513 dibandingkan dengan $\alpha=0,05 \quad\left(\mathrm{t}_{\text {tabel }}=\mathbf{2 , 0 7 3 8 7}\right)$ dengan derajat kebebasan $\mathrm{dk}\left(\mathrm{N}_{1}-1\right)+\left(\mathrm{N}_{2}-1\right)=22$. Dengan demikian $t_{\text {hitung }}<t_{\text {tabel }}$ yaitu 1,513 $<\mathbf{2 , 0 7 3 8 7}$ maka dapat dikatakan bahwa hipotesis $\mathrm{H}_{\mathrm{a}}$ ditolak atau $\mathrm{H}_{0}$ diterima.

Jadi dapat disimpulkan bahwa tidak terdapat perbedaan yang signifikan antara hasil pre-test kemampuan motorik halus anak pada kelompok ekperimen dan kelompok kontrol.

Berdasarkan hasil post-test kemampuan motorik halus anak pada kelompok eksperimen dan kelompok kontrol pada post-test diperoleh nilai rata-rata kelompok eksperimen yaitu 81,2. Angka rata-kelompok kontrol yaitu 74,5. Berdasarkan hasil analisis data yang telah dilakuakan bahwa $t_{\text {hitung }}$ sebesar 1,513 dibandingkan dengan $\alpha=0,05 \quad\left(\mathrm{t}_{\text {tabel }}=\mathbf{2 , 0 7 3 8 7}\right)$ dengan derajat kebebasan $\mathrm{dk}\left(\mathrm{N}_{1}-1\right)+\left(\mathrm{N}_{2}-1\right)=22$. Berdasarkan hasil analisis data yang telah dilakukan bahwa $t_{\text {hitung }}$ sebesar 2,161 dibandingkan dengan $\alpha=0,05 \quad\left(\mathrm{t}_{\text {tabel }}=\mathbf{2 , 0 7 3 8 8 7}\right)$ dengan derajat kebebasan $\mathrm{dk}\left(\mathrm{N}_{1}-1\right)+\left(\mathrm{N}_{2}-1\right)=22$. Dengan demikian $t_{\text {hitung }}>t_{\text {tabel }}$, yaitu 2,161 >2,073887, maka dapat dikatakan bahwa hipotesis $\mathbf{H}_{\mathbf{a}}$ diterima atau $\mathrm{H}_{0}$ ditolak.

Dapat disimpulkan bahwa terdapat pengaruh signifikan dari kegiatan kirigami terhadap kemampuan motorik halus anak usia dini di Taman Kanak-kanak Yayasan Amalan Parupuk Tabing Padang.

Salah satu bentuk kegiatan yang dapat meningkatkan pencapaian perkembangan motorik halus anak usia 5 sampai 6 tahun adalah kirigami. Menurut Temko (2012: 4) kirigami addalah seni melipat, memotong atau 
menggunting kertas menjadi bentuk yang kreatif, bahan yang dibutuhkan juga mudah untuk ditemui seperti kertas, gunting dan lem. Kirigami dapat mengembangkan pembelajaran dibidang seni, matematika, desain grafis dan koordinasi mata-tangan. Menurut Mitarwan (2011: 6) "kirigami merupakan seni memotong kertas yang bisa dipelajari dengan mudah hanya dengan berbekal gunting pada kertas". Namun dalam perkembangannya kirigami mulai pada tataran yang cukup yaitu membuat bentuk yang lebih kompleks berupa dua dimensi maupun tiga dimensi.

Perkembangan motorik halus meningkat menjadi signifikan karena kegiatan kirigami yang dilaksanakan oleh peneliti membuat suasana pembelajaran anak di dalam kelas menjadi ceria dan bersemangat. Karena dalam proses pembuatan kirigami ini menggunakan bahan dan alat yang mudah ditemui seperti kertas berwarna-warni serta menggunakan berbagai macam gambar alam semesta yang membuat anak menjadi antusias dalam melakukan kegiatan kirigami.

Dalam penelitian ini, peneliti mendeskripsikan kirigami adalah kegiatan menggambar bentuk garis lurus, melipat karton manila, selanjtunya menggunting bentuk gambar sesuai dengan tema yaitu alam semesta dengan subtema benda-benda langit, selanjutnya menempel bentuk gambar menjadi lipatan 3 dimensi.

Strategi pembelajaran di dalam kelas juga mendukung kemampuan motorik halus anak meningkat karena dalam melakukan kegiatan kirigami juga diselingi dengan menyayi bersama anak-anak sehingga anakanak menjadi ceria dan pembelajaran kondusif. Dalam kegiatan kirigami juga anak disusun duduknya menjadi melingkar sehingga anak saling membantu apabila temannya mengalami kesulitan.

Berdasarkan pendapat di atas, dapat disimpulkan bahwa kirigami dapat mempengaruhi perkembangan kemampuan motorik halus anak. Pada saat peneliti menggunakan kegiatan kirigami pada kelas eksperimen (B1) di Taman Kanak-kanak Yayasan Amalan Parupuk Tabing Padang, semua anak terlihat antusias dan semangat dalam mengerjakan kegiatan kirigami. Sedangkan di kelas kontrol (B2) membuat origami alam semesta untuk mengembangkan kemampuan motorik halus.
Berdasarkan pengamatan peneliti, kemampuan motorik halus anak kelas eksperimen lebih baik daripada hasil kemampuan motorik halus anak di kelas kontrol. Maka dapat disimpulkan bahwa kirigami berpengaruh terhadap kemampuan motorik halus anak usia dini di taman kanakkanak Yayasan Amalan Parupuk Tabing Padang.

\section{SIMPULAN}

Berdasarkan hasil analisis data yang telah dilakukan, maka dapat diambil kesimpulan sebagai berikut: Berdasarkan hasil penelitian yang dilakukan di Taman Kanakkanak Yayasan Amalan Parupuk Padang hasil kemampuan motorik halus anak di kelas eksperimen (B1) dengan kirigami lebih tinggi dibandingkan dengan anak kelas kontrol (B2) dengan kegiatan origami alam semesta, $(83,25)$ untuk kelas eksperimen dan (76) untuk kelas kontrol.

Pada uji hipotesis diperoleh hasil $t_{\text {hitung }}$ $>t_{\text {tabel }}$ dimana $\left.2,161>2,07387\right)$ yang dibuktikan dengan taraf signifikan $\alpha=0,05$ ini berarti terdapat perbedaan yang signifikan antara hasil kemampuan motorik halus anak pada kelas eksperimen menggunakan kegiatan kirigami dengan kelas kontrol yang menggunakan kegiatan origami alam semesta.

Kirigami terbukti mempunyai perbedaan siginifikan untuk mengembangkan kemampuan motorik halus anak usia dini di Taman Kanak-kanak Yayasan Amalan Parupuk Padang. Hal ini dapat dilihat dari kemampuan motorik halus anak dapat berkembang dengan baik dalam kegiatan menggambar, melipat, menggunting dan menempel.

\section{SARAN}

Terbukti dengan adanya kirigami berpengaruh terhadap kemampuan motorik halus anak, sehingga dapat disarankan kepada guru untuk dijadikan alternatif kegiatan pembelajaran dalam menstimulasi kemampuan motorik halus anak. Kemudia disarankan kepada Sekolah agar dapat memfasilitasi guru dalam rangka pembelajaran inovatif salah satunya dengan kirigami. Hasil penelitian ini dapat dijadikan sebagai salah satu literatur bagi peneliti selanjutnya. 


\section{UCAPAN TERIMA KASIH}

Ketua peneliti beserta anggota mengucapkan terimakasih banyak kepada Tim dan Taman Kanak-Kanak Yayasan Amalan Parupuk Tabing Padang atas kerjasama yang baik selama penelitian ini dilakukan. Kepercayaan lembaga yang diberikan akan terus kami jaga dan akan kami kembangkan terus pada penelitianpenelitian yang akan dating.

\section{DAFTAR RUJUKAN}

Departemen Pendidikan Nasional. 2014. Peraturan Menteri Pendidikan dan Kebudayaan Republik Indonesia Nomor 137. Jakarta: Departemen Pendidikan Nasional.

Beaty, Janice J. 2014. Observing Development Of The Young Child: Seven Edition (alih bahasa Arif Rakhman). Jakarta: Kencana.

Fauziddin, M. (2016). Meningkatkan Kemampuan Kognitif Anak melalui Kegiatan Membilang dengan Metode Bermain Media Kartu Angka . AUDI, 1(2), 60-70.

Gita, Tita Norma \& Julianto. (2016). Pengaruh Kegiatan Kirigami Geometri Terhadap Kemampuan Motorik Halus Anak Kelompok B. Jurnal Paud Teratai. Volume 05 Nomor 02 Tahun. 142-148.

Indonesia, R. (2003). Undang-Undang Nomor 20 Tahun 2003 Sistem Pendidikan Nasional. Jakarta.

Kemendikbud. 2013. Kerangka Dasar dan Struktur Kurikulum 2013. Jakarta: Direktorat Pembinaan Pendidikan Anak Usia Dini.

Mitarwan, Hamid M. 2011. Membuat Gift Cards Kirigami Cinta. Jakarta: Gramedia Pustaka Umum. (Https://Books.Google.Co.Id/Books?Id $=$ Cudodwaaqbaj\&Pg=Pa96\&Lpg=Pa9 6\&Dq, Diakses 14 Maret 2018)

Munawaroh, H. (2017). Pengembangan Model Pembelajaran dengan Permainan Tradisional Engklek sebagai Sarana Stimulasi Perkembangan Anak Usia Dini Di RA Masythoh Singkir Wonosobo. Jurnal Obsesi: Journal of Early Childhood Education, 1(2), 6. https://doi.org/10.31004/obsesi.v1i2.30 4
Mutiah, Diana. 2010. Psikologi Bermain Anak Usia Dini. Jakarta: Kencana.

Novitawati. 2014. Perkembangan Motorik Anak Usia 5-6 Tahun di Tk Islam Selaras Jakarta Timur. (Jurnal Tarbiyah Ilmiah Pendidikan, Vol.3 No 1Januari-Juni 2014,diakses pada 05 Mei 2018)

Santrock, John W. 2007. Child Development (Alih Bahasa Oleh Mila Rahmawati Dan Anna Kuswandi) Edisi Kesebelas. Jakarta: Erlangga.

Sugiyono. 2015. Metode Penelitian Pendidikan Pendekatan Kuantitatif, Kualitatif, Dan $R \& D$. Bandung: Alfabeta.

Syafril. 2010. Stastika. Padang: Sukabina Press.

Temko, Florence. 2012. Ebook:Kirigami Home Decoration. New York: Tuttle Publishing (Https://Books.Google.Co.Id/Books?Id $=$ Xgjqagaaqbaj $\& \mathrm{Hl}=\mathrm{Id} \&$ Source $=\mathrm{Gbs}$ Book_Other_Versions, Diakses Pada 17 Desember 